\title{
Lipofilling after breast conserving surgery: a plastic surgery perspective
}

\author{
Melisa D. Granoff ${ }^{1}$, Lifei Guo ${ }^{2}$, Dhruv Singhal $^{1}$ \\ ${ }^{1}$ Division of Plastic and Reconstructive Surgery, Department of Surgery, Beth Israel Deaconess Medical Center, Harvard Medical School, Boston, \\ MA, USA; ${ }^{2}$ Department of Plastic and Reconstructive Surgery, Lahey Hospital \& Medical Center, Burlington, MA, USA \\ Correspondence to: Dhruv Singhal, MD. Division of Plastic and Reconstructive Surgery, Department of Surgery, Beth Israel Deaconess Medical \\ Center, Harvard Medical School, 110 Francis St, Suite 5A, Boston, MA 02215, USA. Email: dsinghal@bidmc.harvard.edu. \\ Provenance and Peer Review: This article was commissioned by the editorial office, Gland Surgery. The article did not undergo external peer review. \\ Comment on: Cohen S, Sekigami Y, Schwartz T, et al. Lipofilling after breast conserving surgery: a comprehensive literature review investigating its \\ oncologic safety. Gland Surg 2019;8:569-80.
}

Submitted Feb 25, 2020. Accepted for publication Mar 27, 2020.

doi: 10.21037 /gs.2020.04.02

View this article at: http://dx.doi.org/10.21037/gs.2020.04.02

In the recent article Lipofilling after breast conserving surgery: a comprehensive literature review investigating its oncologic safety, a PRISMA and PubMed/MEDLINE literature search was conducted to evaluate the safety of lipofilling after breast conserving surgery (BCS). Inclusion criteria were as follows: (I) the study participants underwent lipofilling following BCS, and (II) the authors reported the recurrence rate. The exclusion criteria included (I) mastectomy or other types of surgery without the patient undergoing BCS prior to lipofilling, (II) non-cancer related reconstruction, (III) in vitro and animal studies, (IV) review articles and meta-analyses, (V) correspondence/commentary, (VI) full text unavailable, (VII) languages other than English without available translation. A total of 19 articles met inclusion/ exclusion criteria. Seven novel and stringent criteria were then applied to these 19 articles to evaluate whether lipofilling after BCS was shown to be safe: (I) description of interval to fat injection, (II) time to follow-up from BCS, (III) time to follow-up from lipofilling, (IV) subgroup analyses, (V) comparison group, (VI) appropriately matched controls, and (VII) powering. Using these rigorous and appropriate evaluation criteria, the study concluded that no published articles proved oncologic safety after meeting all 7 criteria. Their conclusion is that a study that proves patient safety is needed before surgeons routinely proceed with lipofilling after BCS.

While we agree with the authors that the safety of lipofilling after BCS is still very much undecided, it is worth highlighting that reconstructive options exist for patients choosing BCS that would prevent the eventual need for lipofilling. A preventive approach can be taken for patients of all breast sizes. Specifically, therapeutic mammoplasty at the time of lumpectomy is best-suited for larger breasted women, and involves resection of the tumor through reduction mammoplasty incisions, reshaping the breast using reduction mammoplasty or mastopexy techniques (1-5). While the oncologic safety of this approach has been previously determined, the redistribution of breast parenchyma with simultaneous reduction of overlying skin results in a good aesthetic outcome even after radiation. A second option is volume replacement with flap reconstruction (6). This approach is suitable for smaller breasted women, and has tremendous variety, including local perforator-based flaps (lateral, medial and anterior intercostal artery perforators and lateral thoracic artery perforators), thoracodorsal artery perforator flaps, latissimus dorsi flaps, omental flaps, upper abdominal advancement flaps, and free flaps including the transverse upper gracilis flaps. All the above have been shown in the literature to be oncologically safe with good aesthetic outcome, precluding the need for eventual lipofilling.

In our practice, we emphasize prevention of postlumpectomy defects. In close collaboration with the breast surgery service, plastic surgeons pre-operatively evaluate 
breast cancer patients undergoing lumpectomy who have been identified as high risk for a post-lumpectomy defect based on tumor and/or breast size. If patients are deemed adequate candidates for either volume displacement or volume replacement procedures, we will proceed with a combination procedure between the two services. Occasionally, a patient will choose to undergo a mastectomy after counseling from both services. In the rare instance of a patient presenting to our service with a post-lumpectomy defect, we are inclined not to perform fat grafting, but would consider volume replacement and displacement procedures, though we would ideally prefer to perform these procedures prior to the delivery of radiation in order to maintain the soft tissue envelope.

Lipofilling itself has been a topic of concern for plastic surgeons for over 30 years. The governing body of plastic surgeons, the American Society of Plastic Surgeons (ASPS), released a position paper in 1987 that posited that fat grafts would always necrose, would compromise breast cancer detection, and should be prohibited, “...injection of any material into the breast, including autogenous fat, should be condemned" (7). Since then, the plastic surgery community has taken a somewhat less hardline stance. In 2007 the French Society of Plastic Surgery recommended postponing lipofilling regardless of breast cancer status unless carried out in a prospective controlled protocol (8). The ASPS itself revisited this topic and in 2009 organized the Fat Graft Task Force. In its only recommendation since its creation, the task force agreed that the literature lacks large, high-quality studies. The task force evaluated the current literature, which indicated no evidence of interference with breast cancer detection and recommended more studies to confirm these findings. Ultimately, the task force was unable to produce any specific guidelines regarding fat grafts in 2009. Their recommendation was for randomized controlled trials to be conducted on this topic (9). Cohen et al.'s recommendations are aligned with the ASPS recommendations from over a decade ago, pointing to the enormous dearth of appropriate research that has occurred on this topic, despite its enormous potential impact.

We would like to bring attention to a previously written editorial in response to the largest series of lipofilling procedures published to date. Specifically, in 2011, Petit et al. reported on 646 cases of lipofilling in 513 patients including 143 BCS patients in a multi-center study (10). The authors concluded that there is no evidence of interference with breast cancer detection after lipofilling because imaging technology is able to identify the grafted fat versus other lesions. To confirm cancer safety, authors suggested longer follow-up, more patients, and a matched control group. In response to that study, Cordeiro challenged the ability to compare patients between centers due to varying cancer stage, type of cancer, surgical and medical treatment (11). Clearly, standardizing these criteria in a retrospective review is not possible. Cordeiro went further to suggest that future studies on lipofilling should utilize a prospective randomized approach with matched patient cohorts in a multicenter trial and long-term followup of survival (11). Interestingly, almost a decade has passed since that publication and these requirements have not been met by a single study, bringing us to the paper at hand. Will the study or studies needed to answer the question of lipofilling safety with sufficient evidence ever be conducted? And if not, how will we as a community ensure our patients' safety? What will we recommend to them in the interim?

In summary, we commend the authors for the rigor of the criteria with which they evaluated the studies that exist in the literature. The breakdown of how each study met or failed to meet their study criteria is helpful in illuminating the areas in which we as a field must address holes in the literature. Of all the studies addressing lipofilling safety, this one has the highest standards for evaluation of evidence and serves as a call to action for our community to improve the rigor of studies on this topic. We commend and thank Cohen et al. for this sobering and necessary work.

\section{Acknowledgments}

Funding: None.

\section{Footnote}

Conflicts of Interest: All authors have completed the ICMJE uniform disclosure form (available at http://dx.doi.org 10.21037/gs.2020.04.02). The authors have no conflicts of interest to declare.

Ethical Statement: The authors are accountable for all aspects of the work in ensuring that questions related to the accuracy or integrity of any part of the work are appropriately investigated and resolved.

Open Access Statement: This is an Open Access article distributed in accordance with the Creative Commons Attribution-NonCommercial-NoDerivs 4.0 International License (CC BY-NC-ND 4.0), which permits the non- 
commercial replication and distribution of the article with the strict proviso that no changes or edits are made and the original work is properly cited (including links to both the formal publication through the relevant DOI and the license). See: https://creativecommons.org/licenses/by-nc-nd/4.0/.

\section{References}

1. Patel KM, Hannan CM, Gatti ME, et al. A head-tohead comparison of quality of life and aesthetic outcomes following immediate, staged-immediate, and delayed oncoplastic reduction mammaplasty. Plast Reconstr Surg 2011;127:2167-75.

2. Kronowitz SJ, Kuerer HM, Buchholz TA, et al. A management algorithm and practical oncoplastic surgical techniques for repairing partial mastectomy defects. Plast Reconstr Surg 2008;122:1631-47.

3. Spear SL, Pelletiere CV, Wolfe AJ, et al. Experience with reduction mammaplasty combined with breast conservation therapy in the treatment of breast cancer. Plast Reconstr Surg 2003;111:1102-9.

4. Clough KB, Lewis JS, Couturaud B, et al. Oncoplastic techniques allow extensive resections for breast-conserving therapy of breast carcinomas. Ann Surg 2003;237:26-34.

Cite this article as: Granoff MD, Guo L, Singhal D. Lipofilling after breast conserving surgery: a plastic surgery perspective. Gland Surg 2020;9(3):617-619. doi: 10.21037/ gs.2020.04.02
5. Caruso F, Catanuto G, De Meo L, et al. Outcomes of bilateral mammoplasty for early stage breast cancer. Eur J Surg Oncol 2008;34:1143-7.

6. Macmillan RD, McCulley SJ. Oncoplastic breast surgery: what, when and for whom? Curr Breast Cancer Rep 2016;8:112-7.

7. Fat autografting. Plast Reconstr Surg 1987;80:646-7.

8. Petit JY, Botteri E, Lohsiriwat V, et al. Locoregional recurrence risk after lipofilling in breast cancer patients. Ann Oncol 2012;23:582-8.

9. Gutowski KA, ASPS Fat Graft Task Force. Current applications and safety of autologous fat grafts: a report of the ASPS fat graft task force. Plast Reconstr Surg 2009;124:272-80.

10. Petit JY, Lohsiriwat V, Clough KB, et al. The oncologic outcome and immediate surgical complications of lipofilling in breast cancer patients: a multicenter study-Milan-Paris-Lyon experience of 646 lipofilling procedures. Plast Reconstr Surg 2011;128:341-6.

11. Cordeiro PG. Discussion: The oncologic outcome and immediate surgical complications of lipofilling in breast cancer patients: a multicenter study--Milan-Paris-Lyon experience of 646 lipofilling procedures. Plast Reconstr Surg 2011;128:347-8. 